\title{
Reading sentences in Spanish: some similarities and differences between children with dyslexia and those with deafness
}

\author{
Jesús Alegría ${ }^{1}$, María-Soledad Carrillo ${ }^{2}$, Mercedes I. Rueda ${ }^{3}$, and Ana-Belén Domínguez3* \\ 1 Université Libre de Bruxelles (ULB), Belgium). \\ 2 Universidad de Murcia (Spain). \\ 3 Universidad de Salamanca (Spain).
}

\begin{abstract}
Título: Lectura de oraciones en español: similitudes y diferencias entre niños con dislexia y niños con sordera.

Resumen: Este estudio compara las estrategias para leer oraciones utilizadas por un grupo de escolares con dislexia $(n=107)$ y un grupo con sordera e implante coclear $(n=61)$ de lengua castellana. Los resultados indican que solo los participantes con sordera adoptan la estrategia de palabras clave (EPC), que consiste en identificar algunas de las palabras de la oración con contenido semántico propio, e ignorar las palabras funcionales. Se observa además que el uso de la EPC está asociado con un déficit sintáctico. Por otra parte, cuando los dos grupos se emparejan en el nivel lector con niños con desarrollo típico en lectura (Grupo Control, $n=785$ ), las diferencias entre los Grupos Disléxico y Control desaparecieron. Sin embargo, los niños con sordera mantenían su tendencia a usar la EPC y seguían presentando dificultades para procesar las palabras funcionales. Estos resultados excluyen la hipótesis de que la EPC sea un procedimiento utilizado de forma general para compensar los déficits de lectura, pareciendo depender, más específicamente, de dificultades en la capacidad sintáctica.

Palabras clave: dislexia; sordera; implante coclear; lectura; estrategia de palabras clave.
\end{abstract}

\section{Introduction}

Studies comparing dyslexic and deaf persons are scarce (but see Aaron, Keetay, Boyd, Palmatter, \& Wacks, 1998; Herman, Kyle \& Roy, 2019; Herman \& Roy, 2016; Miller, 2005, 2007; Mohammed, Campbell, MacSweeney, Barry, \& Coleman, 2006; Roy, Shergol, Kyle, \& Herman, 2015), despite the possibility that interesting similarities and differences might exist. In the present study only one particular aspect - inspired by deaf research -concerning sentence reading was examined. Several recent studies with deaf persons have shown that most present a tendency to adopt a particular strategy to read sentences - termed the key word strategy (KWS) (see Domínguez \& Alegría, 2010; Domínguez, Carrillo, Pérez, \& Alegría, 2014, with orally educated adults; and Domínguez, Carrillo, González, \& Alegría, 2016, with primary school children with and without cochlear implants). This strategy consists of extracting the meaning from sentences merely by considering the most frequent content words and neglecting the function words and affixes. For example, in a sentence like "Driving too fast on a main road might be dangerous" a KWSreader would probably consider exclusively the morphemes drive, fast, road, and danger, and extract the meaning of the sentence based on them. The empirical support for this hypothesis comes from a comparison of participants' performance

* Correspondence address [Dirección para correspondencia]: Ana-Belén Domínguez. Faculty of Education. University of Salamanca, Paseo de Canalejas, 169. 37008 Salamanca (Spain). E-mail: abd@usal.es (Article received: 23-9-2019, revised: 7-11-2019, accepted: 16-2-2020)
Abstract: The present study compares the strategies to read sentences used by Spanish-speaking children with dyslexia $(n=107)$ and cochlearimplanted children with deafness $(n=61)$. The results show that children with deafness, but not with dyslexia, adopt the key-word-strategy (KWS), which consists of identifying some content words of the sentence while ignoring the function words. Furthermore, it appeared that the KWS was associated with poor syntactic ability. Moreover, when Dyslexic and Deaf Groups were carefully matched at reading level with normally developing children (Control Group, $n=785$ ) all of the differences between dyslexics and normally developing children disappeared. Children with hearing loss however were still slow at dealing with function words and consequently maintained their tendency to use the KWS. These results exclude the hypothesis that the KWS is a broadly used procedure to compensate for reading deficits but seems, rather, to depend on poor syntactic ability.

Keywords: dyslexia; deafness; cochlear implant; reading; key-wordstrategy.

in two formally identical reading tasks. In both cases, a series of written sentences with a missing word were presented to the participants, who, from among four options, had to choose which one correctly completed the sentence. In the basic reading task, the four options were orthographically similar (see the Instruments subsection for an example). The results for this task were compared with those of a similar task but with foils that were compatible with the meaning of the key words of the sentence. For example the previous sentence was presented with the missing word: dangerous, and the four possible answers were: dangerous (the correct response); and travel, petrol, and car, (three semantically compatible foils). The underlying logic was that a reader who adopts the KWS would have greater difficulty when the foils are semantically compatible with the meaning derived from the key-words than in the basic reading task. Domínguez and Alegría (2010) and Domínguez et al. (2014) have shown that deaf readers, carefully matched with hearing controls for the basic reading task, were considerably poorer at performing the reading task with semantic foils. In the study by Domínguez et al. (2014), a group of adult deaf readers who had studied beyond the compulsory minimum level and who had maintained regular reading activity after leaving school, was compared to a group of hearing school children matched for reading level. When the mean reading level in the basic reading test reached $60 \%$ in both groups, the results for the reading task with semantic foils were considerably poorer for the deaf readers than for the hearing controls (35.5\% and $60.1 \%$ respectively). The authors interpreted this result as indicating that the deaf participants presented a def- 
icit in the morphosyntactic processing of written sentences. The main aim of the present study was to examine the possibility that dyslexic children show a tendency, similar to deaf children, to read sentences using the KWS. In addition, whatever the answer, to try to understand why.

An obvious similarity between dyslexic and deaf readers is that they both read poorly. It might be hypothesized that the KWS is just a linguistically impoverished manner to obtain the meaning of a sentence when basic written word processing mechanisms are not fluent. It has been demonstrated that low skilled readers tend to rely on semantic contexts to compensate for poor word identification skills (Perfetti, Goldman, \& Hogaboam, 1979; Stanovich, 1980). These authors compared word reading with and without a semantic context and found that the facilitating effect of the context was greater in the poor than in the good readers group. Moreover the benefit due to the context disappeared completely when word reading in isolation was controlled. Hence, a deficit in written word processing would lead dyslexics to adopt the KWS.

This analysis assumes that the KWS depends on a deficit in word reading. Previous work with deaf persons led to a slightly different hypothesis (Domínguez et al., 2014; Domínguez et al., 2016). Indeed, the KWS implies neglecting the syntactic constraints of the sentence. In the example with semantic foils presented above the responses travel, petrol, and car must be excluded on grammatical grounds. Participants with hearing loss do not seem to adopt grammaticality as a criterion for choosing the response. This hypothesis was tested by means of a reading task similar to the two previously described tasks, but using sentences with a missing function word, and with function words as foils (prepositions, adverbs and conjunctions). This reading task was specifically designed to evaluate the ability to deal with function words, which, unlike content words (nouns, adjectives and verbs), play an intra-sentence syntactic role. It was hypothesized that participants with poor syntactic skills would find the reading task with function words more difficult than the basic reading task. The results show that primary school deaf children do have a specific deficit with function words when their basic reading level is carefully matched with normally developing control readers (Domínguez et al., 2016). This result was not unexpected because it has been amply established that deaf persons, including those who have benefited from a cochlear implant early in life, have a morphosyntactic deficit (Geers, Tobey, Moog, \& Brenner, 2008; Geers \& Hayes, 2010; Hammer, 2010; Le Normand \& MorenoTorres, 2014; Moreno-Pérez, Saldaña, \& Rodríguez-Ortiz, 2015).

In the case of children with hearing loss, the auditory deficit - even when corrected with cochlear Implants - might explain, at least partially, their poor ability in dealing with affixes and function words, which are auditory less salient than content words. In addition, morphosyntactic ability develops as a result of the linguistic bath more than through explicit teaching activity. In the case of dyslexics, deficits in speech perception and auditory processing have also been observed (Noordenbos, \& Serniclaes, 2015; Serniclaes, Van Heghe, Mousty, Carré, \& Sprenger-Charolles. 2004; Tallal, 1980; Werker \& Tees, 1987). Moreover, the literature on dyslexia offers some examples of morphosyntactic deficits (Cantiani, Lorusso, Guasti, Sabisch, \& Männel, 2013; Cantiani, Lorusso, Perego, \& Molteni, 2015; Delage, \& Durrleman, 2018; Wiseheart, Altmann, Park, \& Lombardino, 2009). Working with a variety of experimental paradigms, these authors showed that children, and in some cases young adults, with dyslexia present deficits at dealing with complex syntactic structures (Wiseheart, Altmann, Park, \& Lombardino, 2009). To sum up, several converging observations led us to envisage that dyslexic children will present a deficit in dealing with function words, and, consequently, show a trend to adopt the KWS.

To summarize, the aims of the present study were:

(1) To compare the strategies used by deaf and dyslexic children to read sentences. Previous work has shown that deaf readers use the KWS to process written sentences, and the first question was to determine whether dyslexic children do the same or not. The empirical signature of using the KWS was the gap between the basic reading task and the task with semantic foils, the latter being more difficult than the former for KWS.

(2) The second aim was to investigate the reasons why readers adopt the KWS. It was proposed that the KWS must be related with a poor ability to deal with function words. To examine this hypothesis the ability to deal with function words was compared with the tendency to use the KWS. A deficit in the function-words-task was expected to show a positive correlation with adoption of the KWS.

(3) Finally the questions arising in points (1) and (2) were examined, controlling for the reading level. The question was to determine whether a putative deficit at dealing with function words and its correlative effects concerning the use of the KWS, disappear or not when participants are matched for reading level.

\section{Method}

\section{Participants}

A group of 107 students with dyslexia (aged between 8.25 and 13.25 years, mean 10.49), 61 students with prelingual hearing loss that had received cochlear implants (aged between 6.00 and 13.17 years, mean 9.71), and a comparison group of 785 typically developing students (aged between 6.33 and 12.33 years, mean 8.80 ) participated in the study. All of them attended primary school in state schools or state-aided private schools in different Spanish cities.

The participants with dyslexia (58 boys and 49 girls), whose first language was Spanish, came from 28 schools. They were all enrolled in regular classes, from 3rd to 6th grade (see Table 1 for details). They had been diagnosed by 
the Psycho-Pedagogical Guidance Team of their educational district following the criteria established by Spanish educational regulations including: (1) a reading level 1.5 standard deviations below the norms for their chronological age; (2) an intellectual level within the range considered as normal (no one had an IQ below 85); (3) no one was diagnosed as presenting symptoms of ADHD; (iv) intact hearing and a normal or corrected vision.

The participants with deafness (34 boys and 27 girls) were recruited though the Guidance Team for HearingImpaired Students from 27 schools. They attended mainstream classes using spoken Spanish (45 children) or bilingual schools using spoken Spanish and Spanish Sign Lan- guage ( 16 children). All of them were integrated with normally hearing children in regular classes from $1^{\text {st }}$ to $6^{\text {th }}$ grade (see Table 1 for details). They had received cochlear implants (CI), 38 children before 30 months (mean $=1.67$, range between .67 and 2.5 years) and 23 children after of 30 months (mean $=5.49$, range between 2.58 and 11 years).

The comparison group (400 boys and 385 girls) were from 14 schools and attended the grades (1 to 6$)$ corresponding to their chronological age (see Table 1 for details). All of them followed the typical reading acquisition path, and their scores in the reading test (TECLE) were above the mean score $-1.5 \mathrm{SD}$ of their age and grade.

Table 1. Demographic information on the participants per Group: Dyslexic, Deaf and Control (age in years).

\begin{tabular}{|c|c|c|c|c|c|c|}
\hline & & & & de & & \\
\hline & 1 & 2 & 3 & 4 & 5 & 6 \\
\hline Dyslexic & & & & & & \\
\hline$N$ & & & 28 & 35 & 24 & 20 \\
\hline Mean age (SD) & & & $9.11(.61)$ & $10.17(.63)$ & $11.11(.57)$ & 12.01 \\
\hline Deaf & & & & & & \\
\hline$N$ & 7 & 13 & 9 & 10 & 9 & 13 \\
\hline Mean age (SD) & $6.77(.43)$ & $7.94(.65)$ & $9.59(.56)$ & $10.06(.48)$ & $11.24(.94)$ & $11.80(.54)$ \\
\hline Control & & & & & & \\
\hline$N$ & 169 & 187 & 145 & 94 & 137 & 53 \\
\hline Mean age (SD) & $6.86(.29)$ & $7.75(.34)$ & $8.77(.27)$ & $9.89(.32)$ & $10.77(.30)$ & $11.74(.32)$ \\
\hline
\end{tabular}

\section{Instruments}

The tasks used in the present experiment are taken from a previous work by Domínguez and collaborators (Domínguez \& Alegría, 2010; Domínguez et al., 2014; Domínguez et al., 2016). In none of the tasks did the participants have to speak. The stimuli were written material, which had to be read silently, and the response consisted of choosing one item from among several options (see https://complydis.usal.es/).

\section{Reading Ability Test (READ)}

The reading level of participants $(R E A D)$ was evaluated with TECLE (Marín \& Carrillo, 1999) a multiple-choice sentence completion test. It consisted of 64 sentences with a missing word (e.g., Está viendo... [He is watching...]). The participant had to choose the option that completed the sentence correctly: the correct word (television [television]); and three foils which were orthographically and phonologically similar to the correct response. Two foils were pseudowords (terevision and tetevisión) and the third was a word inconsistent with the sentence (teléfono [telephone]). The participants had to complete as many sentences as they could in 5 minutes. The sentences were ordered by increasing difficulty using variables such as their length and syntactic complexity, as well as the frequency of the component words. Before the test began, four examples were given to the participants, repeating them as many times as necessary until they understood the task. The Cronbach alpha as well as the split-half technique reached high values $(a=.966$ and $r=.986$, respectively).

\section{Semantic Strategy Detection Test (SEM)}

This task was specifically constructed to detect the use of KWS. The test was formally identical to $R E A D$, and consisted of 64 sentences with a missing word. Four alternatives were proposed for each sentence and the participant had to choose the correct one. The four alternatives were appropriate in the semantic context generated with the key word of the sentence. For example, in the sentence: Ir a mucha velocidad con el coche en carretera es... (Driving a car at high speed on the road is...), the correct response was peligroso (dangerous) and the three foils, viaje (journey), potencia (power), and camino (way) were compatible with the global meaning generated with the key words velocidad, coche, and carretera (speed, car and road). As was the case in the READ test, the difficulty of the task increased from the first sentence onwards. The reliability of this task evaluated by the Cronbach alpha and the split-half technique also presented high values (alpha $=.980$ and $r=.992)$.

\section{Syntactic Ability Test (SNT)}

The aim of this test was to evaluate some aspect of the syntactic ability of the participants asking them to complete a sentence in which a function word was missing. The test consisted of 64 sentences with a missing word. Four alternatives were proposed for each sentence and the participant had to choose the correct response. The target words, as well 
as the three distractors, were function words (prepositions, conjunctions or adverbs). Most of the sentences (more than $90 \%$ ) had the same structure: subject (explicit or not), verb, and a complement. The participants' task consisted of finding the function word which correctly completed the sentence. One example might help to understand the logic of the task: Susana mira ... Juan (Susan looks ... John), where the correct response was $a$ (at) and the foils were en (in), de (of), and $e l$ (the). Among the four propositions, $a$ (at) was the only one which correctly introduced the complement a Juan. The three distractors produced ungrammatical sentences.

It was hypothesized that choosing one of the distractors revealed a deficiency in dealing with syntax. Since the task was presented in a reading format, which is inevitable in the case of deaf persons, some reading ability was necessary to deal with the task. The reading dimension was reduced as much as possible by using frequent content words, short sentences (from 4 to 6 words), and, as mentioned before, simple syntactic structures. Unlike in the two other tasks involving reading ability, READ and SEM, the sentence length did not increase from the first sentence onwards. The procedure followed in applying this test was the same as with the READ and SEM. The reliability of this task evaluated by the Cronbach alpha and the split-half technique also presented high values (alpha $=.979$ and $r=.991)$.

\section{Procedure}

The participants were tested in their own classroom, collectively in the group of normally developing children, in small groups (between 1 and 5) in the case of children with dyslexia, or individually in the case of the children with hearing loss. The tasks were explained to the participants with deafness using their preferred method of communication: oral and/or sign language. The first session was devoted to the READ, and the second session to SEM and SNT tasks.

\section{Data analysis}

The number of correct responses per participant, corrected for guessing (number correct responses - (number of errors / (number of alternatives - 1)), was calculated in the three tasks (READ, SEM and SNT) and the scores converted into a percentage of correct responses. The method commonly used to compare the performance of two groups in a task consists of considering their mean score in the task. This method, however, requires that the two groups be adequately matched for age (or reading level if this variable is to be controlled). In the present study this method was unsuitable because participants with dyslexia or deafness presented great variability in age as well as in reading level. This led us to adopt a method (described in detail in the Results section) based on regression analysis, which consists of evaluating the performance in each task using delays instead of raw scores. For example, suppose that the READ-score of a ten-yearold participant was reached by the Control Group at the mean age of eight and half years. The participant's READdelay would be one and a half years). This method permits individual delays to be calculated for each task by comparing the score of a participant with the whole comparison group represented by the regression equation of the group, rather than considering a few participants who have approximately the same age (or the same reading level) as the participant being evaluated.

\section{Results}

\section{Evaluation of the performance in the experimental tasks}

The results of the three tasks (READ, SEM, and SNT) are presented following the same scheme. First, the percentage of correct responses (corrected for guessing, as explained above) for each participant and task, was calculated. Two linear regression equations per group (Control, Dyslexic, and Deaf) and task were then calculated, one considering the percentage of correct responses in the task as a function of the age of the participant, and the other (only for SEM and SNT) as a function of their reading level (READ).

Table 2 represents the parameters of the regression equations (intercepts (a) and slopes (b)) per task and group of participants, as a function of age and of reading level. The corresponding determination coefficients $\left(\mathrm{R}^{2}\right)$ are also included. In order to help with visualizing the results, the data of READ as a function of Age are presented in Figure 1, which shows individual scores and the regression lines per group.

Table 2. Slopes (b), intercepts (a), and coefficients of determination $\left(R^{2}\right)$ of the linear regression equations, considering the percentage of correct responses as a function of chronological age (in READ, SEM and SNT), and as a function of the reading level (in SEM and SNT), per Group (Control, Dyslexic, and $\underline{\text { Deaf). }}$

\begin{tabular}{|c|c|c|c|c|c|c|c|c|c|c|c|c|c|c|c|}
\hline \multirow[b]{2}{*}{$\overline{\text { GROUP }}$} & \multicolumn{3}{|c|}{$\mathrm{READ} * \mathrm{AGE}$} & \multicolumn{3}{|c|}{$\mathrm{SEM} * \mathrm{AGE}$} & \multicolumn{3}{|c|}{$\mathrm{SNT} * \mathrm{AGE}$} & \multicolumn{3}{|c|}{$\mathrm{SEM} * \mathrm{READ}$} & \multicolumn{3}{|c|}{$\mathrm{SNT} * \mathrm{READ}$} \\
\hline & $a$ & $\mathrm{~b}$ & $\mathrm{R}^{2}$ & $a$ & $\mathrm{~b}$ & $\mathrm{R}^{2}$ & $a$ & $\mathrm{~b}$ & $\mathrm{R}^{2}$ & $a$ & $\mathrm{~b}$ & $\mathrm{R}^{2}$ & $a$ & $\mathrm{~b}$ & $\mathrm{R}^{2}$ \\
\hline Control & -45.30 & .82 & $.63^{*}$ & -61.80 & .96 & $.60^{*}$ & -54.98 & .88 & $.627 *$ & -4.73 & 1.07 & $.80^{*}$ & -.85 & .94 & $.76^{*}$ \\
\hline Dyslexic & -28.70 & .46 & $.38^{*}$ & -42.85 & .54 & $.23^{*}$ & -37.29 & .494 & $.24^{*}$ & -8.72 & 1.19 & $.61 *$ & -3.64 & .98 & $.52^{*}$ \\
\hline Deaf & -29.08 & .59 & $.27 *$ & -31.60 & .51 & $.18^{*}$ & -22.65 & .427 & $.19 *$ & -10.39 & .95 & $.81 *$ & -3.39 & .77 & $.78^{*}$ \\
\hline
\end{tabular}




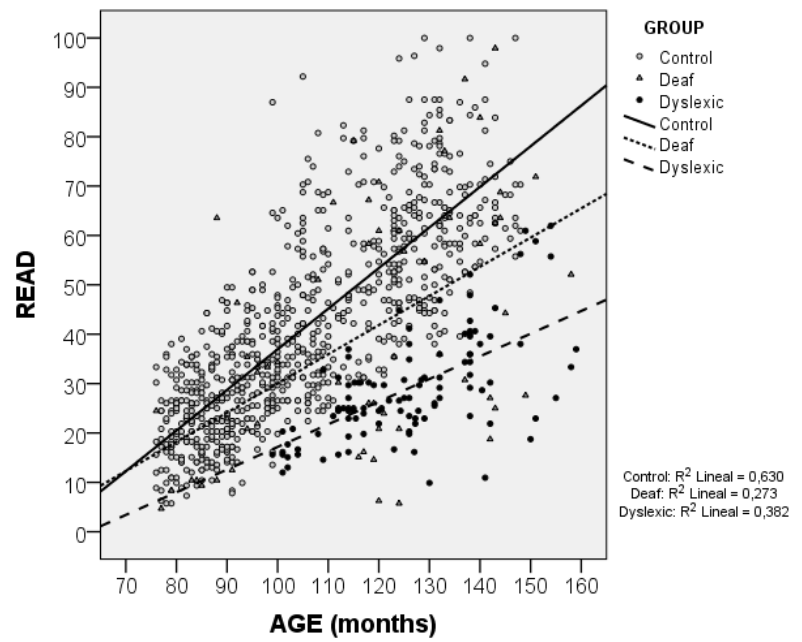

Figure 1. Percentage of correct responses in the READ task as a function of Age. The linear regression lines per Group (Control, Deaf and Dyslexic) are included.

Secondly, individual delays in each task were calculated taking the difference between the age at which a participant reached a particular score in a task (READ, SEM, and SNT) and the age at which the control group as a whole reached the same score.

For example, in the Age Control Analysis, a participant of 120 months of age and with 30 points in the SEM task will have a SEM delay relative to the control participants of the same age (SEM-Da) of -24.47 months. This value was ob- tained using the regression equation of the Control group considering SEM as a function of age: SEM $=.96 \times \mathrm{AGE}-$ 61.80). According to this equation, the Control group reached 30 points in the SEM task at 95.53 months, which is 24.47 months before the participant in our example: Age $=$ $(30+61.80) / .96=95.53$ months; SEM-Da $=95.53-120$ $=-24.47$ months.

The same procedure was used to evaluate the delays in SEM and SNT tasks, relative to reading level (the Reading Control Analysis).

Let us consider that the participant of the above example had a score in the READ test of 25 points. The equation of SEM as a function of READ for the control group (Table 2): SEM $=1.07 \times$ READ -4.73 shows that the SEM score corresponding to 25 points in READ is 22.02 points: $\mathrm{SEM}=$ $1.07 \times 25-4.73=22.02$. Consequently, the participant has a delay of +7.98 points $(30-22.02)$ in the SEM task. This value (delay in SEM-points) was translated into delay in months which is easier to grasp. The equation relating SEM to AGE (Table 2) was used to this end. The slope of the equation indicates that the SEM score increases at a rate of .96 points per month. Therefore, the SEM-Dr of +7.98 points corresponds to a delay of +8.31 months $(7.98 / .96)$ in SEM.

The mean delays in years per group in READ, SEM, and SNT in the Age Control Analysis (READ-Da, SEM-Da and SNT-Da), as well as in the Reading Control Analysis (SEMDr and $S N T-D r$ ), are presented in Figure 2.

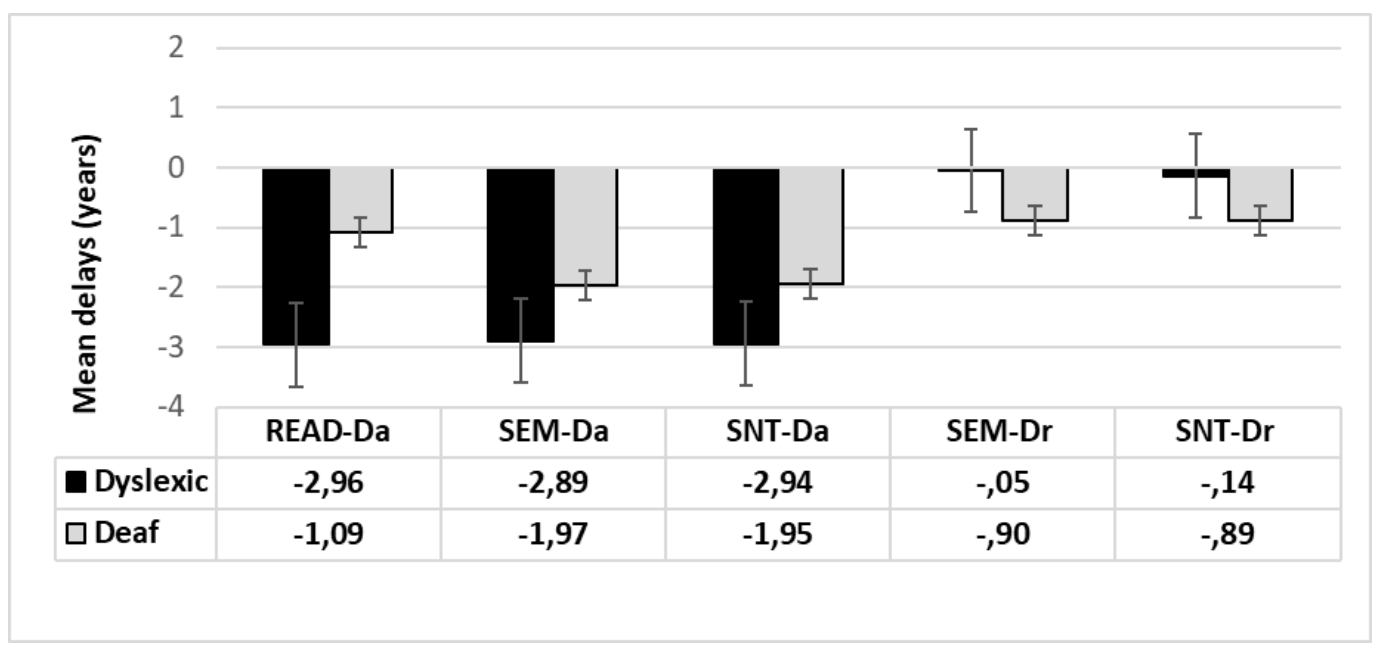

Figure 2. Mean delays, in years, relatively to Age Control (-Da) and Read Control (-Dr) for Dyslexic and Deaf Groups.

The reading level of Dyslexic and of Deaf Groups

Before coming to the question of reading strategy, it will be useful to examine the reading delay of our Dyslexic and Deaf Groups. Figure 1 shows the reading level (READ) as a function of AGE of the participants and the regression lines per group. Close inspection of the figure shows that both groups, Dyslexic and Deaf, are delayed relative to the Con- trols of the same age. This is not a surprise in the case of the participants with dyslexia since they were selected due to their delay in reading. More importantly, the deficit in reading tends to increase with age in both groups. The slopes of the regression lines are .46, .59, and .82 in Dyslexic, Deaf, and Age Controls, respectively. Put in other terms, the mean delays in the Deaf Group increases from 8 to 18 months between $3^{\text {rd }}(100$ months of age $)$ and $6^{\text {th }}$ grade (136 months). In 
the Dyslexic Group the corresponding delays increased from 23 to 39 months in the same period.

\section{Assessment of the Key Word Strategy}

The rationale proposed to establish the extent to which participants adopt the KWS consists of comparing the delay in the basic reading test (READ) with the delay in the SEM task. Greater difficulties in the SEM than in the READ test are the signature of using the KWS. Figure 2 shows the mean delays in READ and SEM in the Age Control Analysis. Children with dyslexia show almost identical delays in both tasks (READ-Da $=-2.96$ and SEM-Da $=-2.89$; $t(106)$ $=-.723 ; n s)$. The Deaf Group, on the contrary, shows a deficit in the SEM task almost double that of the deficit in READ (READ-Da $=-1.09$, and SEM-Da $=-1.97 ; t(60)=$ $6.238 ; p<.001, d=.40)$. This suggests that participants with hearing loss adopted the KWS to some extent, while this tendency in the children with dyslexia, if it existed, did not differ from that of normally evolving readers of the same age.

A more direct way to examine a tendency to use the KWS is to consider the delays of the participants in the SEM task as a function of the reading level (see Figure 2). The results of the Dyslexic and Deaf groups agree with those obtained in the Age Control Analysis. The mean delay of the Dyslexic Group (SEM-Dr $=-.05$ ) did not differ from the mean delay of the Control Group, which was zero $(t(890)=$ $.497, n s)$, while it reached almost one year in the Deaf Group $(S E M-D r=-.90)$, which is significantly greater than the delay of the Control group $(t(844)=7.25, p<.001, d=.96)$.

Finally, it was interesting to consider the possibility that the tendency to adopt the KWS changes with age and/or reading level. To examine this question the correlation between Age and the gap between READ-Da and SEM-Da was calculated. The $r$-value in the Dyslexic and Deaf Groups were $r=.007$; $n s$, and $r=.319 ; p=.012$, respectively. This suggests that the tendency to adopt the KWS increased with age in the Deaf Group, but not in the Dyslexic Group.

\section{Syntactic Ability: dealing with function words}

As argued in the Introduction section, the KWS necessarily involves a tendency to disregard the function words. Accordingly, it was expected that the SNT task would be found harder than the READ task. Figure 2 shows the delays in READ and SNT in the Age Control Analysis. These delays are basically identical in the Dyslexic Group ( $R E A D-D a$ $=-2.96$ years, and $S N T-D a=-2.94$ years; $t(106)=-.177 ; n s)$, indicating that the SNT task does not add difficulty to the basic reading test (READ). In contrast, these two delays in the Deaf Group differed significantly (READ-Da $=-1.09$ years, and SNT-Da $=-1.95$ years; $t(60)=5.651 ; p<.001, d=$ $.41)$, pointing to an extra deficit when dealing with function words.

Another way to examine this question consists of directly comparing the delays in the SNT task in Dyslexic, Deaf and Controls of the same reading level (Figure 2). The absence of any specific difficulty with function words would produce a zero mean delay in the SNT task in all groups. Note that this is necessarily the case in the Control Group. The results are consistent with those obtained when controlling for age. The mean delay of the Dyslexic Group $\left(S N T-D_{r}=-.14\right)$ did not differ from the mean delay of the Control Group $(t(890)=$ $1.39, n s)$ while it reached almost one year in the Deaf Group $\left(S N T-D_{r}=-.89\right)$ and was significantly greater than the delay of the Control Group $(t(844)=6.47, p<.001, d=.89)$.

These results agree with those obtained for delays in the SEM task, meaning that the SNT and SEM tasks are more difficult than the basic Read test in both analyses (Age and Reading Control Analysis) for the Deaf but not for the Dyslexic Group. The readers with deafness showed a strong tendency to neglect the function words of the sentences, suggesting that they have poor syntactic ability. This deficit was directly associated with adoption of the KWS.

In order to assess, as directly as possible, the relationships between syntactic ability and the KWS independently of the reading level, two parameters were considered: the SNT-Dras evaluating the ability to deal with function words, and the SEM-Dr as assessing the tendency to adopt the KWS. It was predicted that these two parameters would be positively correlated. As expected, the correlation coefficients (Pearson's $r$ ) were $r=.524 ; r=.682$; and $r=.508(p<$ .001 , in each case) for Dyslexic, Deaf, and Reading level control Groups, respectively.

\section{Discussion}

\section{The key word reading strategy}

The first goal of this study was to examine the reading strategy used by children with dyslexia and with hearing loss to read sentences. Previous studies have shown that adults with deafness who had reached high levels of education, as well as children with deafness with and without cochlear implants, use a reading strategy, the KWS, which consists of identifying the most frequent content words of the sentence, and deriving its overall meaning on this basis (Domínguez \& Alegría, 2010; Domínguez et al., 2014; Domínguez et al., 2016). Evidence that the KWS was adopted by deaf persons is that the sentence reading task involving foils that were semantically compatible with the meaning of the key words (SEM) was harder than the basic reading test (READ). The new question to which we sought an answer in this study was whether children with dyslexia use the KWS or not, and, whatever the answer to the question - why?

The results are clear-cut. As was expected, compared with controls of the same age, the Deaf Group showed a reading delay in the SEM task twice the delay shown in the basic reading test (-1.97 and -1.09 years respectively). The Dyslexic Group, on the contrary, did not show any additional delay in the SEM task relative to the READ test (-2.96 and 
-2.89 years, respectively). This suggests that dyslexics, despite having a mean reading delay of about three years, did no rely on the KWS. Based on previous research, it was speculated that dyslexics might compensate for their poor reading ability by exploiting the semantic context of the sentences derived from the meaning of some of its content words (Perfetti et al., 1979; Perfetti \& Lesgold, 1977; Stanovich, 1980). This was clearly not the case. So, the notion that the KWS is adopted by all poor readers to compensate for a fluency deficit can be rejected. Indeed, both groups were struggling readers but only the deaf children adopted the KWS. The critical difference between dyslexic and deaf children, which might explain why they differ in their reliance on the KWS, is their syntactic ability - an issue that is examined in the following section.

\section{Syntactic processing of sentences: dealing with function words}

It was argued in the Introduction that the KWS is probably related with poor syntactic skills, and the results confirm this hypothesis. In the Dyslexic Group the delay in the SNT task was almost identical to the delay in READ (-2.94 and 2.96 years, respectively). In the Deaf Group, however, the delay in the SNT task was about twice that measured in the READ test (-1.95 and -1.09 years, respectively), suggesting that children with deafness do have a specific difficulty in dealing with function words. Nonetheless, the Deaf Group presented an extra deficit in both SEM and SNT tasks relative to the basic reading test, while the Dyslexic Group's delay in the three tasks, READ, SEM and SNT, was the same. Finally, if it is admitted that poor syntactic ability is a condition for adopting the KWS, then, these two modes of functioning must be correlated. Actually, the empirical index evaluating the (in)ability to deal with function words and the index evaluating the tendency to adopt the KWS were significantly correlated. The former explained $26 \%$ and $28 \%$ of the latter's variance in dyslexic and control groups, while this value reached $47 \%$ in the Deaf Group. It is tempting to conclude, that the syntactic inability of children with hearing loss is a cause of their tendency to adopt the KWS, and not simply their poor reading skills. Obviously, the present results are merely correlational, and correlations do not allow causal conclusions. Only a longitudinal study demonstrating that successful training in the manipulation of function words reduces the use of KWS in the deaf could be considered as strong evidence of a causal relationship.

The notion of context to explain the use (or not) of KWS remains an intriguing question. Previous experiments on the use of context by poor readers (Perfetti et al., 1979; Perfetti \& Lesgold, 1977; Stanovich, 1980) typically consisted of showing that the final word of a sentence is not treated but simply guessed. For example, a poor reader presented with a sentence like "The singer took his guitar and intoned a pleasant .... (blues)" is more likely to respond song instead of blues than a good reader. It is worth noting that song is gram- matically correct, indicating that poor readers use the semantic context to guess, but they also consider syntactic constrains to elaborate the response. In the present study the foils in the SEM task were all ungrammatical. Dyslexic readers do not adopt the KWS because they do apply the syntactic constraint which eliminate the ungrammatical responses generated by the foils. The deaf readers probably elaborate a context-like model using the key-words and choose the response without taking syntax in consideration.

\section{Controlling for reading level in SEM and SNT read- ing tasks}

The emerging picture when reading level was controlled confirms the conclusions obtained in the Age Control Analysis. The mean delays of the Dyslexic Group were nil when reading level was controlled (-.05 and -.14 years in SEM and SNT tasks, respectively). In contrast, the delays in the Deaf Group decreased from about 2 years in the Age Control Analysis (- 1.97 and - 1.95 in SEM and SNT tasks, respectively) to about one year in the Reading Control Analysis (.90 and - .89 years in SEM and SNT tasks, respectively). Furthermore, these delays remained constant across reading levels. Nonetheless, when children with dyslexia reached a particular reading level, which happened with a mean delay of three years, their delay in SEM and SNT disappeared. This suggests that the reading mechanisms operating do not differ from those of normally developing readers. The notion that persons with dyslexia, because of their poor word processing skills, adopt the KWS, which favours content word processing, in order to increase fluency and/or reduce memory charge was clearly not supported by the present results. The Deaf Group however, continued to have a significant delay in both SEM and SNT when reading level was controlled, corroborating the view that they have a specific problem with function words. This result confirms previous data obtained with deaf adults with high levels of education (Domínguez et al., 2014). It has been repeatedly shown that persons with deafness have a deficit at a morphosyntactic level (Gaustad \& Kelly, 2004; King \& Quigley, 1985; Niederberger, 2007; Paul, 1998; see also, in Spanish, MorenoPérez et al., 2015; Rodríguez, García \& Torres, 1997; Stockseth, 2002). It is likely that readers with deafness use semantically driven strategies to a greater extent than their hearing peers, including dyslexics, because their syntactic ability is poorer.

It remains to be understood why reading activity does not help children with hearing loss to improve their ability in dealing with function words, while it does in children with dyslexia. One obvious reason is that function words would tend to be ignored with the KWS. Consequently, reading activity fails to play its well-established language-teaching role (Cunningham \& Stanovich, 1991; Stanovich, 1986; Stanovich \& Cunningham, 1992). Exposure to speech seems to be indispensable to grasp the role of function words in sentence processing. Content words can be learnt by designation 
and/or by explicit teaching. Function words, however, are passively acquired through simple exposure to spoken material. Following Marschark, Sarchet, Rothen \& Zupan (2010), it is important to understand what is still missing for cochlear implanted children to develop a basic morphosyntactic ability which would prepare them to exploit reading practice to progress in syntactic development. It may be speculated that syntactic morphemes are generally less salient, shorter and unstressed, than content words, so that they remain less accessible for children with hearing losses.

\section{Summary and conclusions}

The clearest summary of the present results appears in Figure 2. The picture given by the Dyslexic Group is straightforward. The children of this group were selected based on their delay in reading ability, which reached a mean value of three years. The fact that the delays in the other tasks were quantitatively similar to the delay in the basic reading test indicated that all of the linguistic and cognitive abilities examined were strongly related to each other. Furthermore, the Reading Control Analysis (Fig. 2) showed that the delays disappeared when reading level was equated. It can be concluded that children with dyslexia, despite their huge reading delay, follow the same path as normally developing children concerning function-word processing and sentence reading strategy, which develop trough reading practice. The present

\section{References}

Aaron, P.G., Keetay, V., Boyd, M. Palmatier, S., \& Wacks, J. (1998). Spelling without phonology: A study of deaf and hearing children. Reading and Writing: An Interdisciplinary Journal, 10, 1-22. doi: 10.1023/A:1007917929226

Cantiani, C., Lorusso, M. L., Guasti, M. T., Sabisch, B., \& Männel, C. (2013). Characterizing the morphosyntactic processing deficit and its relationship to phonology in developmental dyslexia. Neuropsychologia, 51, 1595-1607. doi: 10.1016/j.neuropsychologia.2013.04.009

Cantiani, C., Lorusso, M. L., Perego, P., Molteni, M., \& Guasti, M. T. (2015). Developmental dyslexia with and without language impairment: ERPs reveal qualitative differences in morphosyntactic processing. $D e-$ velopmental Neuropsychology, 40(5), 291-312. doi:10.1080/87565641.2015.1072536

Cunningham, A. E., \& Stanovich, K. E. (1991). Tracking the unique effects of print exposure in children: Associations with vocabulary, general knowledge, and spelling. Journal of Educational Psychology, 83, 264-274. doi:10.1037/0022-0663.83.2.264

Delage, H., \& Durrleman, S. (2018). Developmental dyslexia and specific language impairment: Distinct syntactic profiles? Clinical Linguistics \& Phonetics, 32(8), 1-28. doi:10.1080/02699206.2018.1437222

Domínguez, A. B., \& Alegría, J. (2010). Reading mechanisms in orally educated deaf adults. Journal of Deaf Studies and Deaf Education, 15, 136-148. doi:10.1093/deafed/enp033

Domínguez, A. B., Carrillo, M. S., González, V., \& Alegría, J. (2016). How do deaf children with and without cochlear implants manage to read sentences: The key word strategy. Journal of Deaf Studies and Dead Education, 21, 280-292. doi:10.1093/deafed/enw026

Domínguez, A. B., Carrillo, M. S., Pérez, M., \& Alegría, J. (2014). Analysis of reading strategies in deaf adults as a function of their language and meta-phonological skills. Research in Developmental Disabilities, 35, 14391456. doi:10.1016/j.ridd.2014.03.039 results are compatible with the notion that dyslexics are considerably delayed but not impaired.

The case of children with deafness was different. The Age Control Analysis shows that the delays in the different tasks were not homogenous as they were in the Dyslexic Group. The Deaf Group was specifically delayed in the SNT reading task, which was designed to evaluate the ability of handling function words. The deficit in the SNT task, relative to the basic reading test, suggests that this group had a specific syntactic problem. This would explain their tendency to adopt the KWS which, involves neglecting function words. The Reading Control Analysis adds an important feature to this picture. The Deaf Group's delays in SEM and SNT tasks did not disappear compared with typically developing children of the same reading level. This suggests that the syntactic deficit of children with deafness, as well as their tendency to adopt the KWS, was not reduced by reading practice. This might occur because these children do not process function words while reading sentences. This tentative conclusion needs a training program aimed at reducing their syntactic deficit. The prediction is that an improvement in syntax will simultaneously reduce the delays in SNT and SEM task. Only such a result might permit strong conclusions about the causal nature of the relation between function word processing and the KWS.

Acknowledgment.- Ministerio de Ciencia, Innovación y Universidades (Proyecto PGC2018-094565-B-I00).

Gaustad, M. G., \& Kelly, R. R. (2004). The relationship between reading achievement and morphological word analysis in deaf and hearing students matched for reading level. Journal of Deaf Studies and Deaf Education, 9, 269-285. doi:10.1093/deafed/enh030

Geers A. E., \& Hayes, H. (2010). Reading, writing, and phonological processing skills of adolescents with 10 or more years of cochlear implant experience. Ear and Hearing, 32, 49S-59S. doi:10.1097/AUD.0b013e3181fa41fa

Geers, A., Tobey, E., Moog, J., \& Brenner, C. (2008). Long-term outcomes of cochlear implantation in the preschool years: From elementary grades to high school. International Journal of Audiology, 47(Suppl 2), S21-S30. doi:10.1080/14992020802339167

Hammer, A. (2010). The acquisition of verbal morphology in cocblear-implanted and specific language impaired children. $\mathrm{PhD}$ dissertation, University of Leiden, Utrecht, the Netherlands, LOT.

Herman, R., Kyle, F.E. \& Roy, P. (2019) Literacy and phonological skills in oral deaf children and hearing children with a history of dyslexia. Reading Research Quarterly, 0(0), 1-23. doi:10.1002/rrq.244

Herman, R., \& Roy, P. (2016). Dyslexia and deafness. In M. Marschark \& P. Spencer (Eds.). The Oxford Handbook of Deaf Studies in Language, (pp. 344356). New York, NY: Oxford University Press.

King, C. M., \& Quigley, S. (1985). Reading and deafness. San Diego: CollegeHill Press.

Le Normand M. T., \& Moreno-Torres I. (2014). The role of linguistic and environmental factors on grammatical development in French children with cochlear implants. Lingua, 139, 26-38. doi:10.1016/j.lingua.2013.02.012

Marín, J., \& Carrillo, M. S. (1999). Test Colectivo de Eficacia Lectora (TECLE) [Collective Test of Reading Efficiency]. Universidad de Murcia. Available in A. Cuadro, D. Costa, D. Trias, \& P. Ponce de León (2009). Evaluación del nivel lector. Manual técnico del test de Eficacia Lectora (TECLE) 
[Evaluation of reading level. Technical manual of reading efficiency test]. Montevideo, Uruguay: Prensa Médica Latinoamericana.

Marschark, M., Sarchet, T., Rothen, C., \& Zupan, M. (2010). Will cochlear implants close the reading achievement gap for deaf students? In M. Marschark \& P. E. Spencer (Eds.). The Oxford Handbook of Deaf Studies, Language, and Education. Vol.2. (pp. 127-143). Oxford, UK: Oxford University Press.

Miller, P. (2005). Reading comprehension and its relation to the quality of functional hearing: Evidence from readers with different functional hearing abilities. American Annals of the Deaf, 150, 305-323. doi:10.1353/aad.2005.0031

Miller, P. (2007). The role of spoken and sign language in the retention of written words by prelingually deafened native signers. Journal of Deaf Studies and Deaf Education, 12, 184-208. doi:10.1093/deafed/enl031

Mohammed, T., Campbell, R., Macsweeney, M., Barry, F., \& Coleman, M. (2006). Speech-reading and its association with reading among deaf, hearing and dyslexic individuals. Clinical Linguistics \& Phonetics, 20, 621630. doi:10.1080/02699200500266745

Moreno-Pérez, F. J., Saldaña, D., \& Rodríguez-Ortiz, I. R. (2015). Reading efficiency of deaf and hearing people in Spanish. Journal of Deaf Studies and Deaf Education, 20, 374-384. doi:10.1093/deafed/env030

Niederberger, N. (2007). L'apprentissage de la lecture-écriture chez les enfants sourds. [Reading and writing acquisition in deaf children]. Enfance, 59, 254-262. doi:10.3917/enf.593.0254

Noordenbos, M. W., \& Serniclaes, W. (2015). The categorical perception deficit in dyslexia: A meta-analysis. Scientific Studies of Reading, 19, 340359. doi:10.1080/10888438.2015.1052455

Paul, P. (1998). Literacy and deafness: The development of reading, writing, and literature thought. Boston, Massachusetts: Allyn \& Bacon.

Perfetti, Ch. A., \& Lesgold, A. M. (1977). Discourse comprehension ans sources of individual differences. In M. A Just \& P. A. Carpenter (Eds.), Cognitive processes in comprehension, (pp. 141-183). Hillsdale, NJ: Lawrence Erlbaum Associates.

Perfetti, Ch., Goldman, S. R., \& Hogaboam, T. W. (1979) Reading skill and identification of words in discourse context. Memory \& Cognition 7, 273282. doi:10.3758/BF03197600
Rodríguez, J. M., García, J., \& Torres, S. (1997). El uso de estrategias sintácticas en sujetos sordos [The use of syntactic strategies in deaf people]. Revista de Psicología del Lenguaje, 2, 117-135. Retrieved from http://alfama.sim.ucm.es/wwwisis2/

wwwisis.exe $/[$ in = psyke2.in] $/$ ?format $=$ breve\&boolean $=[$ NR:11358009]

Roy, P., Shergold, Z., Kyle, F.E., \& Herman, R. (2015). Spelling in oral deaf and hearing dyslexic children: A comparison of phonologically plausible errors. Research in Developmental Disabilities, 36, 277-290. doi:10.1016/j.ridd.2014. 10.012

Serniclaes, W., Van Heghe, S., Mousty, Ph., Carré, R., \& Sprenger-Charolles, L. (2004). Allophonic mode of speech perception in dyslexia. Journal of Experimental Child Psychology. 87, 336-361. doi:10.1016/j.jecp.2004.02.001

Stanovich, K. E. (1980). Toward an interactive-compensatory model of individual differences in the development of reading fluency. Reading Research Quarterly, 16, 32-71. doi:10.2307/747348

Stanovich, K. E. (1986). Matthew effects in reading: Some consequences of individual differences in the acquisition of literacy. Reading Research Quarterly, 21, 360-407. doi:10.1598/RRQ.21.4.1

Stanovich, K. E., \& Cunningham, A. E. (1992). Studying the consequences of literacy within a literate society: The cognitive correlates of print exposure. Memory \& Cognition, 20, 51-68. doi:10.3758/BF03208254

Stockseth, D. R. (2002). Comprensión de la sintaxis española por lectores sordos chilenos. Revista Signos, 35, 271-290. doi:10.4067/S071809342002005100017

Tallal, P. (1980). Auditory temporal perception, phonics and reading disabilities in children. Brain and Language, 9, 182-198. doi:10.1016/0093934X (80)90139-X

Werker, J., \& Tees, R. (1987). Speech perception in severely disabled and average reading children. Canadian Journal of Psychology, 41, 48-61. doi: $10.1037 /$ h0084150

Wiseheart, R., Altmann, L.J.P., Park, H., \& Lombardino, L. (2009). Sentence comprehension in young adults with developmental dyslexia. Annals of Dyslexia, 59, 151-167. doi:10.1007/s11881-009-0028-7 